\title{
Bacteriophage evolution drives Pseudomonas aeruginosa PAO1 biofilm diversification
}

\author{
Kerensa McElroy ${ }^{1 *}$, Fabio Luciani ${ }^{2}$, Janice Hui ${ }^{1}$, Scott Rice ${ }^{1}$, Torsten Thomas $^{1}$ \\ From Seventh International Society for Computational Biology (ISCB) Student Council Symposium 2011 \\ Vienna, Austria. 15 July 2011
}

\section{Background}

Pseudomonas aeruginosa infection is the leading cause of death for Cystic Fibrosis patients. Antibiotic resistance is rife, possibly due to high colonising population diversity. Our lab has replicated phenotypic diversification in a P. aeruginosa PAO1 biofilm model of lung infection. To reveal underlying genetic variants, we deep-sequenced PAO1 biofilm samples. Our analysis demonstrates several techniques for extracting meaningful biological information from error-prone sequencing data.

\section{Materials and methods}

DNA was extracted from PAO1 biofilm samples harvested after four and 11 days of growth, and Illumina sequenced to $>1000 x$ coverage. Sequencing was also simulated from computer generated PAO1 haplotypes with our program GemSIM. GemSIM uses real data (e. g., the PhiX control) to generate run-specific error models, facilitating realistic simulation. After optimisation, the program VarScan \{Koboldt, $2009 \# 48$ \} accurately detected SNPs in simulated data with frequencies down to $5 \%$. VarScan was then used to identify SNPs with frequency $>=5 \%$ in the biofilm data.

In high diversity regions, haplotypes were reconstructed using bayesian statistical techniques implemented in the program ShoRAH \{Zagordi, 2010 \#49\}, and validated through analysis of individual reads. (ShoRAH's error-correction algorithm can accurately identify variants in high diversity areas with frequencies down to $0.1 \%$.)

\section{Results and conclusions}

Surprisingly, the PAO1 genome contained only two SNPs, with frequencies around $10 \%$. Both were within a

${ }^{1}$ Centre for Marine Bioinnovation, UNSW, Sydney, NSW 2052, Australia

Full list of author information is available at the end of the article

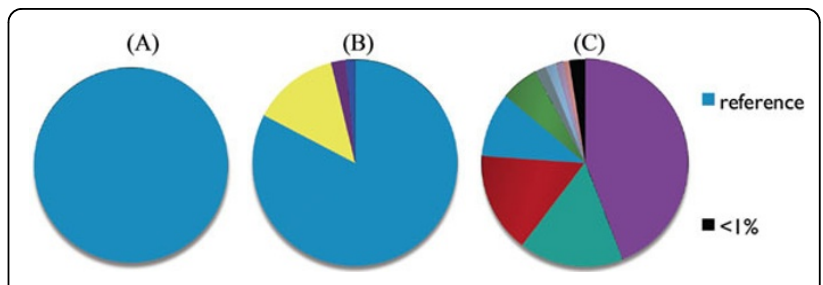

Figure 1 Relative phage haplotype frequencies in PAO1 samples, (A) planktonic, (B) biofilm 4 days, (C) biofilm 11 days.

large hypothetical outer-membrane protein postulated to be involved in biofilm formation and antibiotic resistance. Both SNPs were silent; however converted rare codons to more common ones, potentially increasing expression. These SNPs may reflect early biofilm lifestyle adaptation.

In contrast to the negligible genetic diversity of PAO1, its associated bacteriophage Pf4 revealed ongoing diversification, characterised by an increase in Shannon's entropy between days four and 11 and an explosion in phage population size. All phage SNPs were within or upstream from the putative Repressor $C$ gene. This gene is implicated in Pf4 superinfectivity, which results in loss of host resistance and conversion from a lysogenic form to a lethal, lytic lifecycle.

In total, nine Pf4 haplotypes with frequencies > 1\% emerged by day 11, while the original haplotype dropped to 9\% (Fig. 1). These results suggest superinfective phage haplotype emergence drives diversification within PAO1 biofilms.

\footnotetext{
Author details

${ }^{1}$ Centre for Marine Bioinnovation, UNSW, Sydney, NSW 2052, Australia. ${ }^{2}$ Inflammatory Diseases Research Unit, UNSW, Sydney, NSW 2052, Australia.
}

Published: 21 November 2011 


\section{References}

1. Koboldt DC, Chen K, Wylie T, Larson DE, McLellan MD, Mardis ER, Weinstock GM, Wilson RK, Ding L: VarScan: variant detection in massively parallel sequencing of individual and pooled samples. Bioinformatics 2009, 25:2283-2285.

2. Zagordi $\mathrm{O}$, Klein R, Däumer $\mathrm{M}$, Beerenwinkel $\mathrm{N}$ : Error correction of nextgeneration sequencing data and reliable estimation of HIV quasispecies. Nucleic Acids Res 2010, 38:7400-7409.

doi:10.1186/1471-2105-12-S11-A2

Cite this article as: McElroy et al:: Bacteriophage evolution drives

Pseudomonas aeruginosa PAO1 biofilm diversification. BMC Bioinformatics 2011 12(Suppl 11):A2.

Submit your next manuscript to BioMed Central and take full advantage of:

- Convenient online submission

- Thorough peer review

- No space constraints or color figure charges

- Immediate publication on acceptance

- Inclusion in PubMed, CAS, Scopus and Google Scholar

- Research which is freely available for redistribution

Submit your manuscript at www.biomedcentral.com/submit
C Biomed Central 